\title{
CHARLES ERIKSEN \\ Past, Present, and Future
}

\author{
ARTHUR KRAMER, MICHAEL COLES, and BARBARA ERIKSEN \\ University of Illinois, Urbana-Champaign, Illinois \\ WENDELL GARNER \\ Yale University, New Haven, Connecticut
}

JAMES HOFFMAN

University of Delaware, Newark, Delaware

and

JOSEPH LAPPIN

Vanderbilt University, Nashville, Tennessee

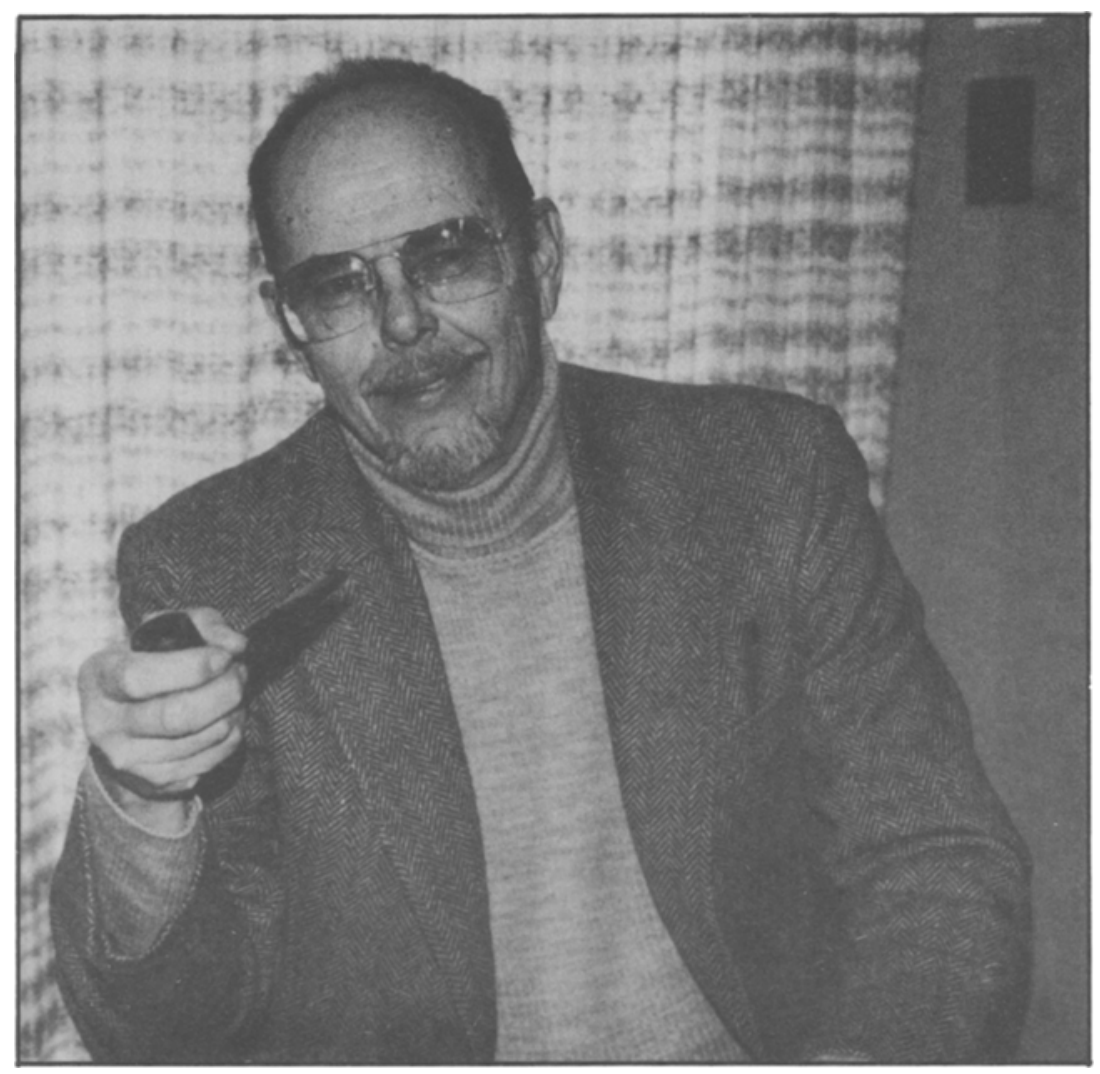

Charles W. Eriksen

Editor's note: Charles Eriksen retired as Editor of Perception \& Psychophysics at the end of 1993. He had served as Principal Editor of this journal since July 1971. This article is offered as a tribute to Charles Eriksen on the occasion of his retirement. 
It is always a difficult task to summarize a lifetime of important scientific discoveries within the confines of a few pages. In the present case, this was all too true, given Charles (Erik) Eriksen's long list of achievements in the fields of experimental and clinical psychology. Erik's varied and interesting exploits outside the field of psychology proper are also quite notable, and to do justice to them would require volumes rather than pages. So, with these caveats in mind, we, colleagues, friends, and former students, have attempted in the following pages to provide a glimpse into the professional and personal interactions that we have had with Erik over the past 40 years.

\section{Beginnings ..... (Barbara Eriksen)}

Erik was born and grew up in Omaha, Nebraska, the oldest of three children. His favorite childhood memories included going fishing and hunting with his father along the Missouri and Platte rivers, and spending summers with his aunts and uncles on their farms in western Iowa and Nebraska. He also got into plenty of mischief, from relatively innocent pranks, like putting a potato in someone's tailpipe or disconnecting the trolley from its electric line, to the more ambitious attempt, with a friend, to steal a stiff from the basement of a mortuary. He claims his life of crime was never detected, except when he and his cousin played chicken by running back and forth in front of the train that ran by his uncle's farm. The engineer almost had a stroke, and the railroad officials soon made a call on his uncle. More constructively, on the farm, he learned to drive the hayrack team and, in his teens, worked on a combine crew. He lost the latter job because he ate so much the farmer figured he was losing money on him.

Academically, Erik remembers grade school as pretty dull and routine. It wasn't until he was skipped from seventh grade into high school that it occurred to him he might be above average. In high school, he particularly enjoyed the debate team, physics, and math classes, and electric shop. He graduated at the head of his class and received a small scholarship to the University of Nebraska at Omaha. Those were still depression times. He had to work full time, in order to augment the scholarship, as well as to help out at home, which made it impossible for him to take the science classes he wanted since he didn't have time for the labs. He ended up with psychology and economics as his major fields of study.

Meanwhile, World War II had broken out. Erik enlisted and went off to basic training at Camp Roberts, California. He resisted many attempts to keep him stateside, working in a psychological testing unit. Instead, as an infantryman, he landed in Normandy four weeks after Dday and fought all the way across Europe until, with Patton's army, his outfit met the Russian army at the agreed upon location. At one point, he received the dubious distinction of a personal commendation from General Patton: As usual, during the long, miserable trek, his platoon was dirty and unshaven. Erik had been called back to headquarters and was able to get a shave, a shower, and a clean uniform. He'd just gotten back to his outfit when General Patton came roaring up in his famous Jeep. He looked over the troops, pointed to Erik, and said, "Now that's the way a soldier ought to look!" His comrades made the most of that phrase for the rest of the war.

Erik's decision to pursue psychology as a career illustrates how relentlessly fate pursues those who are about to head off on the wrong track. When he went to Stanford to begin postgraduate work, physics and psychology were both located in the same building in the corner of the quad. Physics was on the first floor, psychology on the second. Erik had planned to talk to the Physics Department about entering, but when he got there, there was a long line at the Physics Department office. He decided to go upstairs and see what was happening at Psychology. No one was waiting there. He was immediately ushered in to see Ernest Hilgard, a very persuasive man. An hour later, Erik left, signed up in psychology. He got his $\mathrm{PhD}$ in clinical psychology, but had already concluded he was more interested in experimental work than in psychotherapy. Once at Johns Hopkins, he began pursuing that interest, with results that are documented elsewhere in this account.

\section{The Early Years (W. R. Garner)}

It was in 1950 that I first met Charles (Erik) Eriksen. The circumstances were these: At Johns Hopkins University there were two vacancies at the Assistant Professor level. One was in the Psychology Department proper, and the other was in the Student Psychological Clinic. We decided that rather than hiring two distinctly different people, we would combine the two positions, thus hiring two people, each of whom would be half-time at the Clinic and half-time in the Department. Since the Department was strongly research oriented, this decision meant that we wanted two psychologists who would not only be clinicians but would also do research.

In an effort to fill still another position, I went on a tour of the country interviewing candidates. Since one candidate was at Berkeley, I did double duty by going to Stanford to interview a candidate for the Department-Clinic position. My opinion was that the candidate would be fine for the clinical work, but I didn't think he would be likely to do research. I mentioned my reservations to a friend, Donald Taylor, and he suggested that I might want to look at another student who was finishing his degree, and whose name was Charles Eriksen. I did interview him, and considered him very likely to do research, thus feeling he would fit into the Hopkins situation quite well. I returned to Baltimore and gave my report to Clifford Morgan, Chair of the Department. Morgan accepted my judgment, Erik was offered the job, and he accepted it.

At this time, the idea of being a clinician and also doing research was quite new. Clinical psychologists did clinical work and experimental psychologists did experiments, and the two activities were considered incompatible. But attitudes were changing, and the term "experimental clinical psychologist" came into being. Such 
people were soon in great demand. From the time he arrived at Hopkins, Eriksen was quickly perceived as one of these desirable types, with the result that Harvard offered him a position in 1953, just three years after his arrival at Hopkins. But Erik was not happy at Harvard, and returned to Hopkins just a year later. Just another year later, in 1955, Eriksen was offered an Associate Professorship at the University of Illinois (he delayed going there until 1956), again as an experimental clinical psychologist. I felt both pleased and irritated that a small university like Hopkins had raised the sort of person that a large university like Illinois felt the need to hire-pleased because Erik had done so well in our setting, but irritated because I didn't want to see him leave us. Illinois also hired Harold Hake from us the same year. Two from our small faculty seemed unreasonable, but there was nothing I could do about it.

What about the research Erik was doing? He had done his dissertation on the problem of perceptual defense. He continued work along that line when he came to Hopkins, as well as other "clinical type" research on topics such as subception, learning without awareness, and other unconscious processes. It was this research that made his reputation grow rapidly, and that led to his being offered the positions at Harvard and Illinois.

Yet, while his research and reputation were doing so well along this line, an insidious invasion into his life was occurring. Almost as soon as Erik arrived at Hopkins, I began to get him involved in straight perceptual research. He published one paper a year on visual search in 1952, 1953 , and 1954, in addition to more frequent publications on clinical issues. By 1955 , the research on perception increased to three papers, jointly authored with Hake, and to two more with Hake in the following 2 years. These papers were on absolute judgments of stimuli, especially with stimuli generated on multiple dimensions. This research was every bit as good as his clinical research, even though it was not initially his primary activity.

When Erik went to Illinois, it was as an experimental clinical psychologist, and for several years the clinical research was dominant, although there was an occasional paper on perception. But gradually there was a shift toward more and more of his research being strictly experimental, primarily perceptual. His publications show that by 1964 he had become an experimental psychologist, with the oxymoronic term experimental-clinical essentially having disappeared from his life.

There is one last interaction with Erik that I want to describe, and it is perhaps the most important one. I had been having trouble with journal editors when I wanted to describe perception as something that went on in the head, because the simple operationism dominant at the time said that only the observable stimuli and responses were operationally definable, and that there was no such thing as "in the head." The responses were the perceptions. Erik (and Hake) had been having the same sort of trouble, so we agreed to write a theoretical paper on the problem. In the extra hot and humid summer of 1955 , we three met several times a week for several weeks to work out an outline of the paper, and then I wrote the first draft, which was followed by more hot and humid sessions. The paper, "Operationism and the concept of perception," appeared in Psychological Review in 1956, shortly before Erik left for Illinois. That paper emphasized the need for converging operations, and made clear that with such operations it was possible to make valid statements about nonobservable concepts such as perception. This paper made the term "converging operations" part of the psychologist's jargon, and did a very good job of obliterating the simplistic, raw operationism of the time.

It is of interest to note that Erik's participation in our outlining sessions and his contribution to the paper were as an experimental clinical psychologist, with emphasis on perceptual defense. So Erik's move to being an ordinary experimental psychologist did not occur suddenly, but evolved over a period of years. I suspect that people familiar with Erik's research in the past two decades may not even be aware that he was quite famous in his earlier years as an experimental clinical psychologist. But indeed he was!

\section{From a Graduate Student's Perspective in the 1960's (Joseph Lappin)}

My knowledge of Erik stems mainly from my experiences as a graduate student at Illinois from 1962 to 1966 , although we have maintained contact off and on since then and our friendship has been refreshed again in recent years. My perspective as a graduate student was certainly limited, and my memories have doubtlessly been reshaped by intervening experiences, but such limitations may not be so important in describing Erik. Some characteristics seem so salient they will never be forgotten; and even if some details are not fully accurate, the overall picture would not be confused with that of someone else. To those who don't know Erik, descriptions may seem fictitious and exaggerated; but to those who know him, there is the opposite danger, that words may be insufficient.

One of the first times I recall seeing Erik was when he was scheduled for a presentation to the proseminar series for first-year graduate students. His appearance and style contrasted with those of other faculty I had seen at Illinois. Erik was (and is) an imposing figure, about 61/2 feet tall, but slender and powerful-looking. His stride, posture, and movements were visibly self-confident, suggesting that either he was in charge or he didn't give a damn who was. In place of the then-universal professor's uniform of sport coat and tie, Erik wore jeans, wool shirt, and leather boots. The image these clothes projected accorded with the quality of his voice and style of speech: clear and resonant, commanding and definite, with no hint of uncertainty or qualification, but also articulate and surprisingly insightful, and sparked with puckish and ribald humor. These characteristics are familiar to anyone who knows Erik, and my memory has no doubt been supplemented by such familiarity, because Erik actually said very little. In contrast to the faculty who preceded him, 
Erik felt that professors spent too much time lecturing. and at one proseminar announced that he had just written and reproduced for us a paper on personality and perception which covered everything he cared to say, and that our time would best be spent by our reading this paper. He then promptly strode from the room, leaving the surprised supervisor of the proseminar almost speechless.

Little or nothing in Erik's behavior suggested that he welcomed contacts with students or that he cared anything about their ideas or interests. Most graduate students seemed a bit afraid of Erik, and before I began working with him, I thought this was understandable. Although several students worked apparently happily in his laboratory, I think that while I was at Illinois no students outside his supervision ever asked him to serve on their thesis committees. Dr. (Harold) Hake, though, played a different role. (Virtually all faculty were known to graduate students then as "Dr.," so I will use that title here. I initially made the mistake of applying the same title to Erik, but it quickly became clear that he had little patience with such deferential barriers. "Dr. Eriksen" was inappropriate then, so I will maintain the same form of address that I struggled with then.) As Director of Graduate Studies for the Experimental Division, Dr. Hake had a lot of contact with graduate students, and he was clearly supportive and interested in our well-being. After a month or two at Illinois, I was discussing, with Dr. Hake, some ideas about selective attention, which was the focus of my initial interests in psychology, and he suggested that I should see Erik about these interests. So I knocked on Erik's door with predictable trepidation. To my surprise, he did not send me away and even described an experiment that I could work on in his laboratory!

The experiment was not ambitious and I did not initially see much connection to the grand theoretical issues I had in mind, but it was a promising opportunity. Erik proposed that we repeat an experiment on reaction time (RT) recently reported by Helson and Steger, where the RT to a visual light flash was found to be inhibited by the presentation of a second visual stimulus about $100 \mathrm{msec}$ or more after the first stimulus. Erik doubted the validity of this phenomenon, but was interested in its apparent similarity with backward-masking effects, about which, for both methodological and conceptual reasons, he was also skeptical. This experiment resulted in my first publication (Lappin \& Eriksen, 1964), but more importantly, it provided the first of many lessons from Erik about the logic of research. It was also the beginning of my continuing friendship with Erik and of my admiration for the vitality of his personality and intellect and for the profundity of his understanding of research.

On a personal level, I cannot imagine a more effective and enjoyable mentor. Contrary to the intimidating image he had for many graduate students (and probably a few of the faculty as well), Erik's role with his students was personable and unpretentious. Informality was maintained in many ways with humorous criticism of everyone, including himself, and a continuing program of both verbal and practical jokes. Indeed, it became apparent that Erik really enjoyed people, especially those who were least inclined to treat him seriously. Regular noontime dart games in the lab with Mort Weir and Chuck Hullin ("Dr." was inappropriate for any faculty who came to the lab regularly) and other graduate students, including Jim Collins, Jack Thompson, Tom Greenspon, and Ira Bernstein, who was a postdoc, were one of the activities that supported the informal culture of the lab. Rather than being intimidating, Erik fostered both our enjoyment and our selfconfidence as developing scientists.

One of the most obvious characteristics of Erik's style of thinking is his skepticism. When Erik commented on a paper or theoretical idea, it was usually with disdain and usually concerned a failure to include necessary experimental controls or a failure to test the implications of some hypothesis. One simply could not be around Erik and still maintain any reverence at all for the infallibility of the scientific method in mortal hands. No one else I've known has approached the incisiveness of Erik's critical understanding of experimental methodology. This critical attitude was not mere cynicism but reflected a keen understanding of the connections between observation and inference.

Erik has a rare intuitive knack for translating theoretical concepts and hypotheses into experimental operations that directly clarify their meaning. One of my first experiences with this direct approach occurred after we had failed to replicate the Helson and Steger result on the inhibition of a reaction-time response by a second stimulus. Erik then asked whether subjects were even able to inhibit their responses to an earlier stimulus if they were explicitly asked to try to do so. Erik proposed an experiment in which subjects were asked to try to inhibit their responses on occasional trials when a second stimulus was presented. Moreover, to ensure that the subjects did, in fact, respond to the first stimulus and not merely hesitate to check on the potential appearance of a delayed stop signal, they were asked to respond so rapidly that they would sometimes be unable to inhibit their responses when the stop signal appeared. We used conditions in which a stop signal was presented on a randomly selected one-third of the trials, and for half of these the stop signal occurred simultaneously with the go signal and on the other onesixth of the trials, the stop signal was delayed very slightly, with the value of the delay varied between separate blocks of trials.

To Erik, in particular, it was intuitively clear that these data should provide direct information about how the initiation of a response was related to the occurrence of stimulus events occurring in the first few milliseconds following an initial go signal. Initially, however, it was far from clear to me just how we were to extract such information from data that involved interdependencies among (a) RTs for trials on which the go signal alone was presented, (b) probabilities of successfully inhibiting the response on stop-signal trials, and (c) RTs that occurred erroneously on trials with stop signals. Our eventual solution to this 
problem involved converging operations, abandoning the usual assumption that the observed RT was a direct measure of the speed of a perceptual response and using instead the covariation of multiple response variables (Lappin \& C. W. Eriksen, 1966).

By plotting the two RT distributions on the same graph, those for trials with the go signal alone and those for trials with a stop signal on which the subject failed to inhibit the response, it became clear that the lower tails of both distributions were essentially the same and that the two distributions separated from one another as the RT increased above some critical value. In accord with the instructions and demands of the task, the average RTs to the go signal alone increased slightly when half of the stop signals were delayed, and the probability of successfully inhibiting the response to the simultaneous stop signals increased concomitantly. The critical RT for inhibiting the responses to simultaneous stop signals, however, appeared to remain approximately invariant under these changes in mean RT. Moreover, when we compared the value of the critical $R T$ s for inhibiting the response to the delayed stop signals, we found that these RTs were longer than those for the simultaneous stop signals by about the same amount of time as the delay of the stop signal, even for brief delays of 12 to $63 \mathrm{msec}$. Thus, these critical RT values exhibited greater stability and a tighter relationship with the temporal parameters of the stimuli than did the RTs as such. Much of the variability in the RTs was evidently associated with initiating the motor response rather than with actual visual responses to the onsets of the lights. This study is one of many examples of Erik's contributions to the methodology for separating perceptual and response effects and was a precursor to later work by me and others on the speed-accuracy tradeoff.

These studies grew out of Erik's broader interests in perceptual interactions between distinct stimuli at neighboring positions in space and time, in selective attention, and in the temporal characteristics of perception and attention. When I began working with him in the early 1960 s, Erik was in the early phases of several lines of research on these topics. Another of my early exposures to Erik's skill in designing direct tests of theoretical concepts involved an experiment on backward masking. Experiments in the early 60 s had demonstrated that the presentation of a homogeneous luminous field immediately following a briefly exposed matrix of characters greatly reduced subjects' abilities to report the contents of the preceding display. Such backward masking phenomena were usually attributed to an "erasure" of iconic visual storage by the subsequent blank "informationless" field. Erik revealed the fallacy of such theoretical interpretations by showing that essentially the same masking was also produced by presenting the blank light flash before the test forms (Eriksen \& Lappin, 1964; Eriksen 1966). Obviously, the concept of "erasure" from memory made no sense if the information to be erased did not yet exist. Erik's insight was that the backward as well as the forward masking were attributable to temporal luminance summation and consequent contrast reduction of the test forms.

Erik and his students conducted a series of experiments in the 1960 s that served to clarify popular misconceptions about perceptual masking, showing that most of these phenomena involved visual temporal integration rather than interference in "processing" successive percepts. Studies with Jim Collins (C. W. Eriksen \& Collins, 1967, 1968) are elegant examples of this line of research. They presented two patterns of randomly arranged dots which formed recognizable letters when the two patterns were superimposed but which were unrecognizable when the two were seen separately. When the two components were successively presented with a sufficiently brief ISI, the global form was accurately identified, and identification accuracy improved as the ISI was shortened over the same range that produced masking in other experiments. Thus, it was again obvious that the second pattern did not erase or interfere with processing the first stimulus. Rather, the temporally separate components were simply integrated.

One of Erik's early experiments on selective attention, with Hal Johnson (1964), was completed shortly before I began working in his lab. He and Johnson measured the detectability of a soft tone presented at infrequent intervals while a subject was relaxed in an easy chair, reading a novel. The subject was alerted to the possible occurrence of a tone by a momentary blinking of the reading lamp, at which time the subject was to indicate whether or not the tone had occurred. Detectability of the tone was shown to be much lower under such conditions of inattention and declined over brief delays of a few seconds between the tone and the visual signal. Such experiments illustrated the profound effect of attention in selecting information from the broad stream of sensory stimulation.

Erik's exceptionally fruitful research program on visual attention began around this time, mainly during the 1960 s. Erik's most important scientific contributions are probably those associated with this line of research. His experiments offered new and elegant descriptions of these fundamentally important phenomena and also provided rigorous objective methods for their study. Some of the most ingenious and important of these experiments concerned the temporal characteristics of attention and response selection. Most of this wonderful line of research developed after I had left Illinois, but the time I was there was extremely stimulating, productive, and fun. In any event, it was my extraordinary good luck to have begun my scientific career under Erik's supervision. No other event in my career has had such a profound and beneficial effect as my training and friendship with Erik.

\section{Illinois in the 1970s (James Hoffman)}

I met Charles Eriksen in 1968. I was a junior at the University of Illinois, a refugee from electrical engineering. I had taken introductory psychology and knew that I was interested in perception and cognition. I was sure that my background would be useful in these areas and I wrote to Harry Hake to inquire about any research jobs 
that might be available. A few weeks later, I received a call from Dr. Eriksen, inviting me to come in and discuss a summer job at the VA hospital in Danville, a town neighboring the University. When I arrived at the appointed location in Gregory Hall, Erik (as he introduced himself) and his wife, Barbara, showed me around the lab, which was populated primarily by three-field tachistoscopes and Hunter timers. I was given a desk, a project, and a large packet of Erik's reprints.

Erik was not what I expected and certainly didn't fit the "academic image." He was big, about 6'5" and 220 lbs., wore jeans and cowboy boots, and had a very down-to-earth manner. He liked to fish, hunt, and play practical jokes. He was a great story teller and many of his stories revolved around past practical jokes that had been particularly effective. He told with great relish how he and another colleague would sneak into a mutual acquaintance's office and increase the desk height half-aturn per day. This apparently went on for months, a kind of psychological desensitization to desk height. Finally, seeing their victim using a desk that was now at shoulder height and almost useless, they took pity and let him off the hook. He also told, with great glee, how they exchanged two neighboring faculty office doors while the unwitting victims were at lunch. One of them came back, struggled with the key, looked at the name on the door, stepped back and scanned the hallway in puzzlement before finally proceeding to the door with his name on it. Of course, when he opened the door his shock was just beginning as he was confronted with its unfamiliar contents. All this was accompanied by muffled laughter as Erik and his cohorts observed the scene from the end of the hall. There was some talk about taking the graduate student from Chicago (me) on a "snipe hunt." This had apparently been done with good effect with previous city slickers. I heard enthusiastic recounting of previous snipe hunts, the thrill of the chase, etc. I guess Erik took mercy on me because the hunt was never initiated.

The lab at that time was involved in the last of the experiments on visual masking. In between dart games involving myself, John Rohrbaugh, Bob Colgate, and Erik, a second theme was emerging, namely an attempt to understand the nature of limitations in the perception of simultaneous forms. This would be the core of Erik's work for the next several decades and its roots can be found in his earliest papers dealing with visual search. Several papers (C. W. Eriksen \& Lappin, 1967) had shown that the perception and identification of simultaneous forms could be described by a model that assumed parallel and independent processing of multiple forms. The main difficulty seemed to arise at a "decision stage" where perceptions had to be mapped into responses. "Noise" in this decision process could be mistaken for limitations in earlier processes concerned with the extraction of basic shape information. A particularly important example of this approach was the paper by C. W. Eriksen and Spencer (1969), which showed that detection of visual targets was unaffected by the rate at which they were presented.

In contrast to the work supporting independent, unlimited-capacity models was the work by Sperling and Averbach and Coriell which showed that subjects had severe limits in how much information they could remember. In addition, it showed that subjects could use a partialreport cue presented shortly after display onset to selectively encode information into memory. This paradigm showed the existence of a high-capacity visual memory (iconic memory), but Erik realized that, in addition, it provided an ideal tool for studying the deployment of covert attention in vision. Several papers appeared which explored the basic parameters of attentional allocation, including the time course (C. W. Eriksen \& Collins, 1969) and spatial resolution (C. W. Eriksen \& Rohrbaugh, 1970).

Our first paper together (C. W. Eriksen \& Hoffman, 1972) was primarily an attempt to calibrate the RT method by applying it to a paradigm that had been partially explored by using brief presentations and measures of report accuracy. C. W. Eriksen and Collins (1969) had already shown that a cue presented before a display could improve report accuracy, even when the time from the cue to the display was too short to allow an eye movement to occur. We performed a similar experiment and found a reduction in RT. We also found that subjects were slower with more items in the display, even at the longest lead times of the cue. The decreasing RT with increasing lead times of the cue was taken as evidence that allocation of attention takes as long as 200-300 msec for completion. The display-size effect could be due to either one of two factors. One possibility was that subjects had to pay "some attention" to all the display letters, even the irrelevant ones. As Erik pointed out, subjects could report things like how many items were there even if that wasn't part of their task.

An alternative reason for the display-size effect was raised in a paper by C. W. Eriksen and Rohrbaugh (1970), who showed that subjects sometimes incorrectly reported the letter adjacent to the cued one. Increasing number of display items usually correlated with increasing density. Perhaps spatial proximity was responsible for the display-size effect. In fact, when the number of items was held constant, there was a spacing effect (Eriksen \& Hoffman, 1972). Interference was reduced when letters were removed more than about $1^{\circ}$ of visual angle from the cued location.

The deleterious effects of items adjacent to the attended one could be due to contour inhibition or to interference arising at later information-processing stages such as those involved in decision making or response programming. The RT methodology provided a ready method of investigating this issue. Suppose that an attended item was flanked by items evoking an incompatible response. This response incompatibility would obviously matter only if the flanking item were processed all the way to the point 
of evoking their responses. In fact, this was found to be the case (C. W. Eriksen \& Hoffman, 1973). Erik and Barbara Eriksen went on to show that this held even when the attended item was shown in the center of the fovea, without any spatial uncertainty whatsoever.

The processing of to-be-ignored letters adjacent to the cued one suggested that attention could be likened to a "zoom" lens which, at a wide setting, can provide lowresolution information about the entire visual field or can be "zoomed" to provide high-resolution information about a restricted area. The stubborn intrusion of adjacent items suggested that spatial attention may have a limit to its "focus," which was about $1^{\circ}$ of visual angle in these experiments. The attended shape as well as other forms within the attentional field were processed in parallel to a "high" level, high enough to be mapped into their corresponding motor responses. This conception was a precursor to the continuous flow model of RT proposed by C. W. Eriksen and Schultz (1979). According to this conception, all inputs in the visual field are mapped into their corresponding responses in parallel, with the degree of response activation being determined by attention and a variety of other factors, such as discriminability, retinal eccentricity, etc.

\section{The 1980s and Beyond .... (Michael Coles and Arthur Kramer)}

The 1980s saw the continued application of the concept of "continuous flow" (Eriksen \& Schultz, 1978), a concept that had emerged as a result of studies of the "flanker effect" that had been conducted in the 1970s. In these studies (e.g., C. W. Eriksen \& Hoffman, 1973; B. A. Eriksen \& C. W. Eriksen, 1974), reaction times to target stimuli were shown to be affected by the presence of "noise," when the noise was associated with a different response. These data turned out to have profound implications in several ways. First, the data indicated that responses can apparently compete with each other. In a task situation, where only one response is deemed to be correct on any trial, the activation of both correct and incorrect responses results in their mutual inhibition and a resultant slowing of the correct response. Such an account of the "flanker effect" was consistent with interpretations of the well-known Stroop effect, but it emphasized the fact that the Stroop phenomenon was much more general than had been previously believed. The "flankereffect" data also suggested the idea of a continuous flow of information between stimulus-analysis and response systems. Such an idea was, of course, antithetical to the assumptions underlying the use of the additive factors and subtraction procedures that were prevalent in the area. However, the continuous-flow ideas were entirely consistent with other developing concepts that were being articulated by McClelland (1979) and by Grice and his colleagues (Grice, Nullmeyer, \& Spiker, 1982) at around the same time.

In the studies of the flanker effect, the presence of response competition had been inferred quite indirectly from
RT measures. In response to a need for more direct evidence, Eriksen turned to psychophysiology-again. In the 50 s and 60 s, he had flirted with autonomic psychophysiology, but now he became more seriously involved with central nervous system measures. In discussions with colleagues at Illinois, it became clear that notions of response competition and continuous flow could fruitfully be explored using measures of motor-system activity. Thus, first with Coles, Morris, and O'Hara (1985) and later with Coles, Gratton, Donchin, and other colleagues (1985, 1988), psychophysiological evidence was obtained that supported these two ideas. First, flankers that call for the incorrect response are, indeed, associated with incorrect electromyographic activity as well as with more central incorrect response activation. Furthermore, this incorrect activity is accompanied by a delay and disruption in the execution of the correct response. Second, the presence of this incorrect activity, in advance of correct response execution, was entirely consistent with the continuousflow model.

While entirely satisfactory, this adventure in psychophysiology did not lead to a cessation of other research activities. In fact, it was and continues to be accompanied by a relentless attack on a number of different problems using more traditional measurement techniques. First, consideration of various attentional phenomena gave rise to the "zoom-lens" model of perception (Eriksen \& Yeh, 1985), and a variety of empirical studies followed that both supported this conception and challenged alternative views, such as the spotlight model. Second, the relationship between automatic and focused attention has been explored in a number of different studies (C. W. Eriksen, Webb, \& Fournier, 1990). Third, the concepts of response competition and continuous flow have been applied to account for the "fast same effect" in same-different judgments (St. James \& C. W. Eriksen, 1991).

Although Erik formally retired in the summer of 1993, there has been no indication that his theoretical and methodological contributions will slow anytime soon. We, and many other colleagues and former students, look forward to many more years of Erik's incisive scientific insights and, of course, his practical jokes!

\section{REFERENCES}

Coles, M. G., Gratton, G., Bashore, T., Eriksen, C. W., \& DonCHIN, E. (1985). A psychophysiological investigation of the continuous flow model of human information processing. Journal of Experimental Psychology: Human Perception \& Performance, 11, 529-553.

ERIKSEN, B. A., \& ERIKSEN, C. W. (1974). Effects of noise letters upon identification of a target letter in a nonsearch task. Perception \& Psychophysics, 16, 143-149.

ERIKSEN, C. W. (1966). Temporal luminance summation effects in backward and forward masking. Perception \& Psychophysics, 1, 87-92.

Eriksen, C. W., Coles, M. G. H., Morris, L. R., \& O'Hara, W. P. (1985). An electromyographic examination of response competition. Bulletin of the Psychonomic Society, 23, 165-168.

ERIKSEN, C. W., \& Collins J. (1967). Some temporal characteristics 
of visual pattern perception. Journal of Experimental Psychology, 74, 476-484.

Eriksen, C. W., \& Collins J. (1968). Sensory traces versus the psychological moment in the temporal organization of form. Journal of Experimental Psychology, 77, 376-382.

ERIKSEN, C. W., \& Collins, J. (1969). Temporal course of selective attention. Journal of Experimental Psychology, 80, 254-261.

Eriksen, C. W., \& Hoffman, J. E. (1972). Temporal and spatial characteristics of selective encoding from visual displays. Perception \& Psychophysics, 12, 201-204.

Eriksen, C. W., \& Hoffman, J. E. (1973). The extent of processing of noise elements during selective encoding from visual displays. Perception \& Psychophysics, 14, 155-160.

ERIKSEN, C. W., \& JohNSON, H. (1964). Storage and decay characteristics of nonattended auditory stimuli. Journal of Experimental Psychology, 68, 28-36.

ERIKSEN, C. W., LAPPIN, J. S. (1964). Luminance summation-contrast reduction as a basis for certain forward and backward masking effects. Psychonomic Science, 1, 313-314.

ERIKSEN, C. W., \& LAPPIN, J. S. (1967). Selective attention and very short-term recognition memory for nonsense forms. Joumal of Experimental Psychology, 78, 358-364.

Eriksen, C. W., \& Rohrbaugh, J. (1970). Visual masking in multielement displays. Journal of Experimental Psychology, 83, 147-154.

ERIKSEN, C. W., \& SChultz, D. W. (1978). Temporal factors in visual information processing. In $\mathrm{J}$. Requin (Ed.), Attention and performance VII (pp. 3-23). New York: Academic Press.

ERIKSEN, C. W., \& SChUltZ, D. W. (1979). Information processing in visual search: A continuous flow conception and experimental results. Perception \& Psychophysics, 25, 249-263.

ERIKSEN, C. W., \& SPENCER, T. (1969). Rate of information process- ing in visual perception: Some results and methodological considerations. Journal of Experimental Psychology Monographs, 79, Part 2, 1-16.

Eriksen, C. W., Webi, J. M., \& Fournier, L. R. (1990). How much processing do nonattended stimuli receive? Apparently very little, but --. Perception \& Psychophysics, 47, 477-488.

ErIKSEN, C. W., YEH, Y.-Y. (1985). Allocation of attention in the visual field. Journal of Experimental Psychology: Human Perception \& Performance, 11, 583-597.

GARneR, W. R., HAKE, H. W., ERIKSEN, C. W. (1956). Operationism and the concept of perception. Psychological Review, 63, 149-159.

Gratton, G., Coles, M., Sirevaag, E., Eriksen, C. W., \& DonCHIN, E. (1988). Pre- and post-stimulus activation of response channels: A psychophysiological analysis. Journal of Experimental Psychology: Human Perception \& Performance, 44, 331-344.

Grice, G. R., NUllmeyer, R., \& SPIKeR, V. (1982). Human reaction times: Toward a general theory. Journal of Experimental Psychology: General, 111, 135-153.

LAPPIN, J. S., \& ERIKSEN, C. W. (1964). Inhibition of a simple visual reaction time by a second stimulus: A failure to replicate. Psychonomic Science, 1, 293-294.

LAPPIN, J. S., \& ERIKSEN, C. W. (1966). Use of a delayed signal to stop a visual reaction-time response. Journal of Experimental Psychology, 72, 805-811.

MCClelland, J. (1979). On the time relations of mental processes: An examination of systems of processes in cascade. Psychological Review, 86, 287-330.

ST. JAMES, J., \& ERIKSEN, C. W. (1991). Response competition produces a "fast same effect" in same-different judgments. In G. Lockhead \& J. Pomerantz (Eds.), The perception of structure (pp. 157168). Washington, DC: American Psychological Association. 